\title{
MAINTENANCE PERFORMANCE RESEARCH - PART 2: A REVIEW OF MODELS AND FUTURE DIRECTIONS
}

\author{
S. A. Oke \\ Department of Mechanical Engineering \\ University of Lagos, Nigeria \\ sa_oke@yahoo.com
}

\begin{abstract}
In recent years, the research scope of maintenance performance has been greatly expanded due to the pressure on maintenance organizations to deliver fruitful results in the current competitive business environment. In part 1 of this paper, treatment methods and maintenance performance models have been explored. In this concluding paper (part 2), the review further investigates maintenance performance models. The paper offers directions on future research in the area of maintenance performance.
\end{abstract}

\section{OPSOMMING}

As gevolg van die ondervinding van verbruikers in die jongste tyd word organisasies wat instandhouding pleeg, genoop om deel te neem aan kontemporêre navorsing, wat belofte op verbeterde vertoning inhou. Die eerste gedeelte van hierdie artikel behandel metodes en modelle wat gebruik word. Die tweede gedeelte gaan dan voort om modelle van instandhoudingsvertoning te ondersoek. Die aangebode stof word ten slotte aangevul met raadgewing oor moontlike toekomstige navorsing. 


\section{INTRODUCTION}

Maintenance performance measurement, analysis, and control were probably developed during the Second World War, since enormous maintenance activities occurred at that time due to the need to maintain military equipment. Since 1960, some published papers have appeared on maintenance performance [1, 17, 38, 45]. These vary from reviews to rigorous mathematical analysis of specific problems [2$7,9-11,3,15,18,19,23-25]$. Unfortunately, the maintenance practitioner is not helped at all well to find practical ways of controlling the maintenance organisation's output, and thus properly to serve the company's performance. A lot of the 'analysis paralysis' does not bring him nearer to being able to measure maintenance performance in a practical, usable way. The work by Luck [38], Priel [46] and a few others still presents the more practical approach to this problem.

Subsequently, there have been papers that deal with the analysis of a wide range of problems. Unfortunately, for the most part writers have devoted themselves to the analysis of mathematical models rather than to the analysis of problems. This has two consequences. Firstly, the reader is usually required to 'translate' the models presented in the papers into the real world context. In the real world, few problems are simple and many practical difficulties exist. Secondly, analysis of mathematical models requires skill and mathematical expertise that not many researchers possess.

From this review, it may be safe to state that documentation in form of texts or research papers received very little attention until relatively recently (i.e. the second half of the 1990s, evident from the dates of the papers reviewed in this work) when maintenance performance achieved recognition as a subject worthy of academic study in courses, learned journals and articles (see[40-42,47]). Since then a large number of researchers have provided investigative studies that opened the way to further research. Also, maintenance performance has been recognised as becoming more and more important to research students in many quantitative disciplines such as economics, statistics, and industrial and mechanical engineering.

Maintenance performance attempts to provide a systematic and rational approach to the fundamental problems involved in the control of maintenance systems. By using all available information, decision-makers achieve the best results for the benefit of the maintenance function [20,39].

The remaining section of the article is made up of six distinct modules. Section 2 is structured into seven subsections. The first six subsections discuss different approaches in maintenance performance, while the last subsection is an evaluation of all the approaches discussed in the research papers reviewed in parts 1 and 2. In all, twelve different methods were analyzed in the two papers where the review of maintenance performance research has been attempted by the current author. Twenty-five criteria were used to evaluate the approaches. Section 3 discusses maintenance performance in the software area. In section 4, the implications for researchers and managers are discussed based on the author's experience on the papers reviewed. Section 5 presents future directions of maintenance performance research based on the review done on the models presented in the first and second 
parts of this paper. Finally, section 6 provides a conclusion to the study based on the insights gained in this research exploration exercise.

\section{TREATMENT METHODS IN MAINTENANCE PERFORMANCE}

The following provides additions to the methods of maintenance performance treated in part 1 of this paper.

\subsection{Treatment method 1: Value based (VB) and balanced scorecard (BSC) approaches}

The value based and balanced scorecard approaches are popular in the maintenance performance literature in view of their acceptable analytical viewpoint of solving problems [21-43]. The value-based approach emphasizes the value rather than the cost of maintenance in the emerging business environment, extending understanding beyond the purely financial implications of maintenance [2, 37, 49].

The balanced scorecard (BSC) is a vehicle that translates a business unit's mission and strategy into a set of objectives with quantitative measures built around four perspectives: financial, customer, internal process, and learning and growth [15, 37, 49]. The following briefly reviews the literature on the value based and balanced scorecard approaches.

\subsubsection{The value based approach}

This takes into account the impact of maintenance activities on the future value of the organization [2-7]. Mathematical models that could assist in calculating the performance of an organization when the value of the maintenance function is considered have been developed. In a case by Dwight [3], the expression for performance is defined as follows:

Performance $=\frac{\mathrm{V}_{\mathrm{r}}-\mathrm{V}_{\mathrm{i}}}{\mathrm{V}_{\mathrm{r}}^{*}}$

The expression involves three items: the value realized in the period, the cash flow during an interval, and the future value lost compared with the best known value. These are represented by $V_{r},(t-1, t)$ and $V_{i}$. However, it should be noted that $V_{r}$ is equivalent to $C F(t-1, t)$ and $V_{r}^{*}$ (from the performance expression above) is given by $\mathrm{V}_{\mathrm{r}}^{*}=\mathrm{V}^{*}(\mathrm{t}-1)$ where $\mathrm{V}^{*}(\mathrm{t})$ is the estimated best attainable sum of future real cash flows or 'residual value' in the system at time t.

The calculation of $\mathrm{V}^{*}(\mathrm{t})$ and $\mathrm{V}_{\mathrm{i}}$ is suggested to be ex post facto, given the circumstances that prevail during the period under consideration. A common assumption in the development of such a model is that the best available will be taken up in the next period. Alternatively, Dwight [3] proposed another definition of performance. It is suggested that the data required in determining the above 
performance method should be collected from an existing system with the use of a conceptual model known as 'incident evaluation approach' [3]. This approach involves compiling a library of possible primary incidents and their associated actions leading to secondary incidents. An incident could be defined as a failure mode of the system, which will reduce the potential output of the system.

The expression for expected residual value of an action policy is as follows [3]:

$$
\sum_{i=1}^{N}\left(\mathrm{P}\left(\mathrm{C}_{\mathrm{i}}\right) \mathrm{CF}_{\mathrm{i}}\right) \mid \mathrm{A}
$$
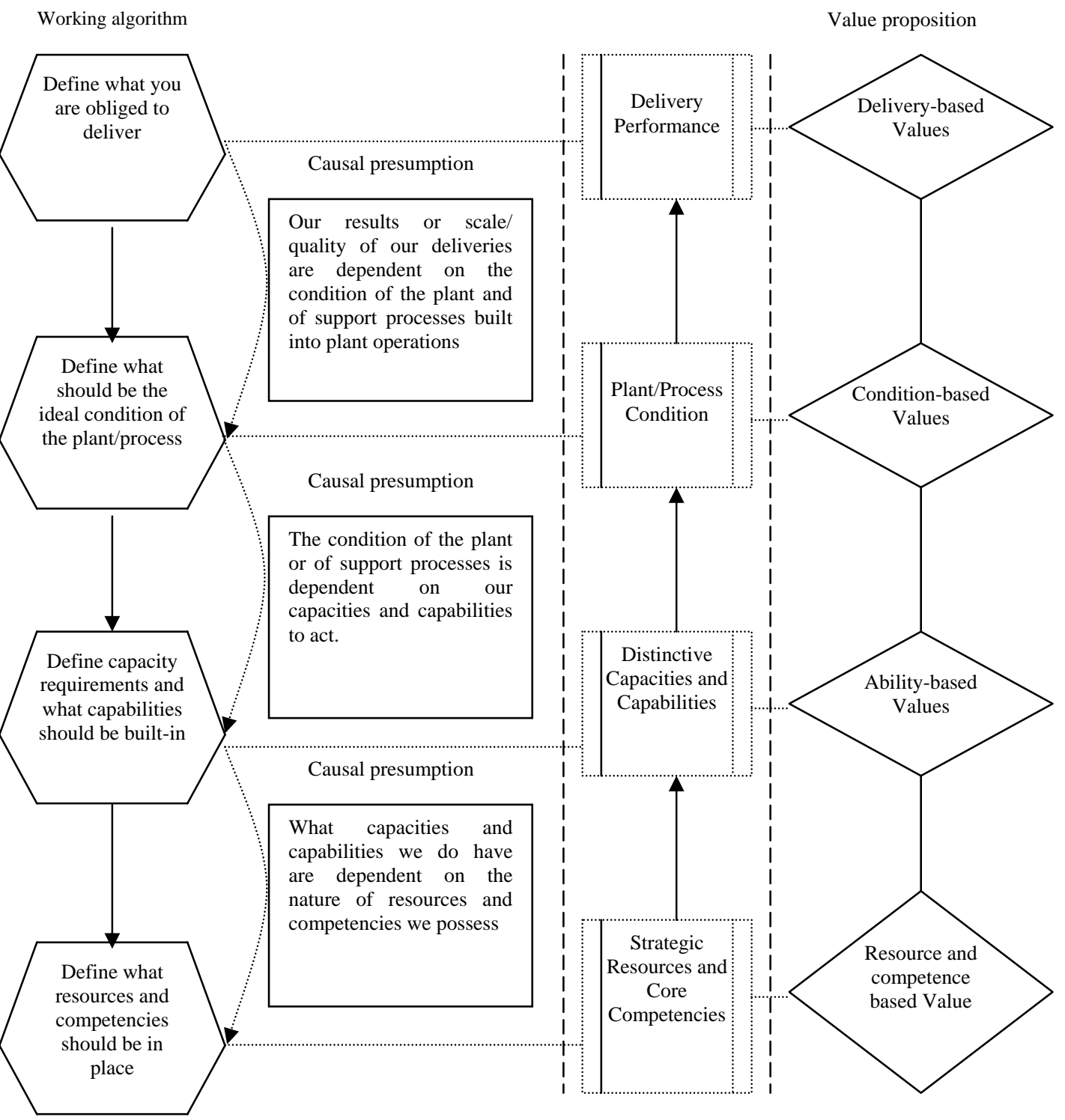

Figure 1: Theoretical configuration of the value based operations and maintenance performance concept [26] 
In the above expression, $\mathrm{P}\left(\mathrm{C}_{\mathrm{i}}\right)$ represents the probability of occurrence of incident $\mathrm{C}_{\mathrm{i}}$ as a function of time. $\mathrm{CF}_{\mathrm{i}}$ is the expected cash flow as a result of $\mathrm{C}_{\mathrm{i}}$ occurring at its expected time, given the available resources implied by action set A. Tsang et al [49] noted that the optimal action policy and $\mathrm{V}^{*}(\mathrm{t}-1)$ are determined ex post facto by taking into account the involuntary incidents that actually occurred during the interval $(\mathrm{t}-1, \mathrm{t})$.

Figure 1 shows the important components of value added performance [26] based on some value propositions.

However, it is possible to view value based management in economic perspective. This idea was presented in a paper by Liyanage et al [26]. The diagram in support of this is shown in Figure 2.

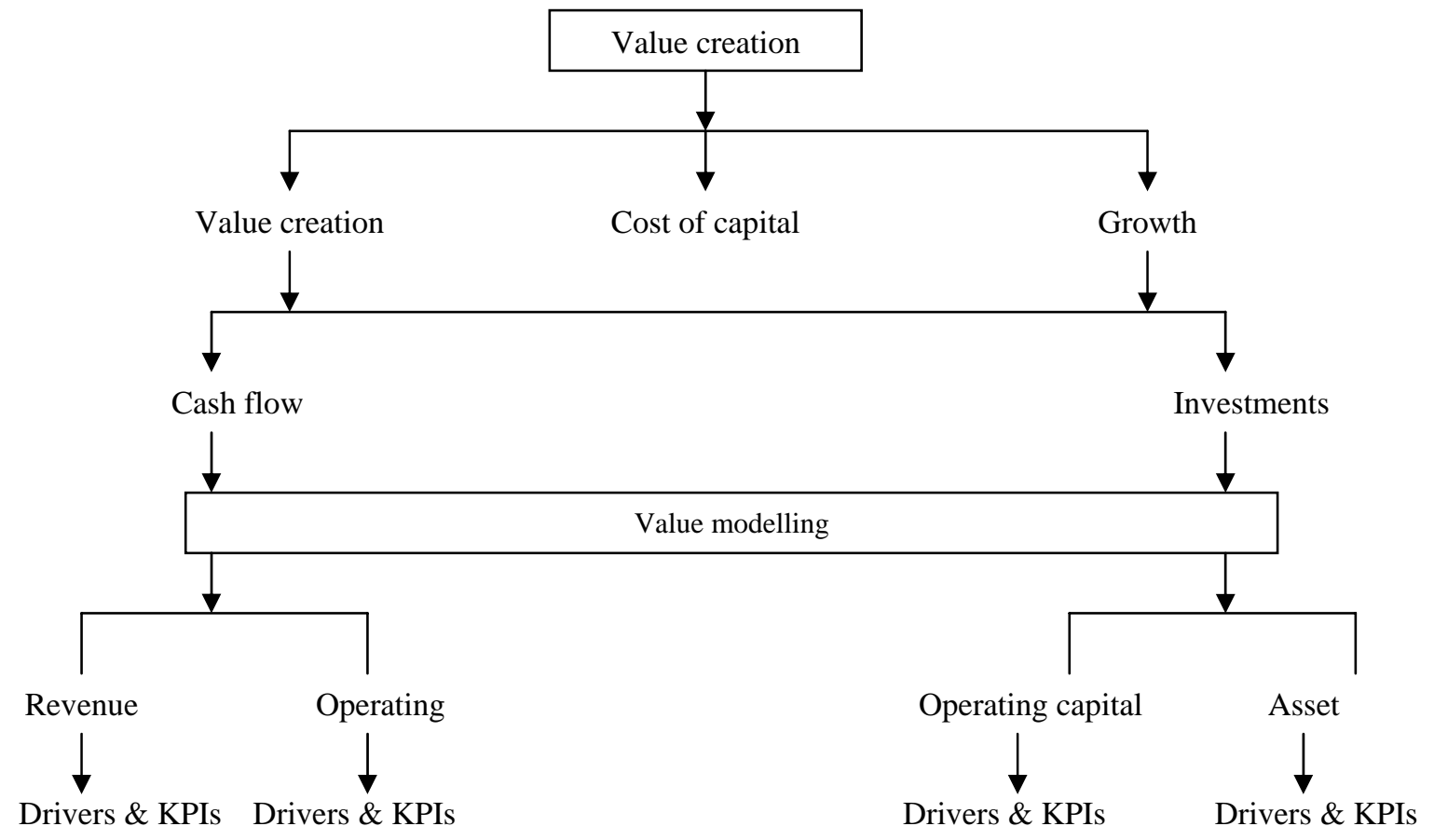

Figure 2: Value-based management in economic perspective [26]

\subsubsection{The balanced scorecard}

The balanced scorecard (BSC) was introduced by Kaplan and Norton [14] as a template for the balanced presentation of analysis [49]. It builds on four perspectives: financial, customer, internal process, and learning and growth [49]. The balanced scorecard has been implemented in a number of major corporations in the engineering, construction, microelectronics and computer industries [15]. Experience in these pioneering organizations indicates that the scorecard will have the greatest impact on business performance only if it is used to drive a change process. The development of a balanced scorecard also engenders the emergence of a strategic management system that links long-term strategic objectives to short-term actions (see Figure 3) [16]. 


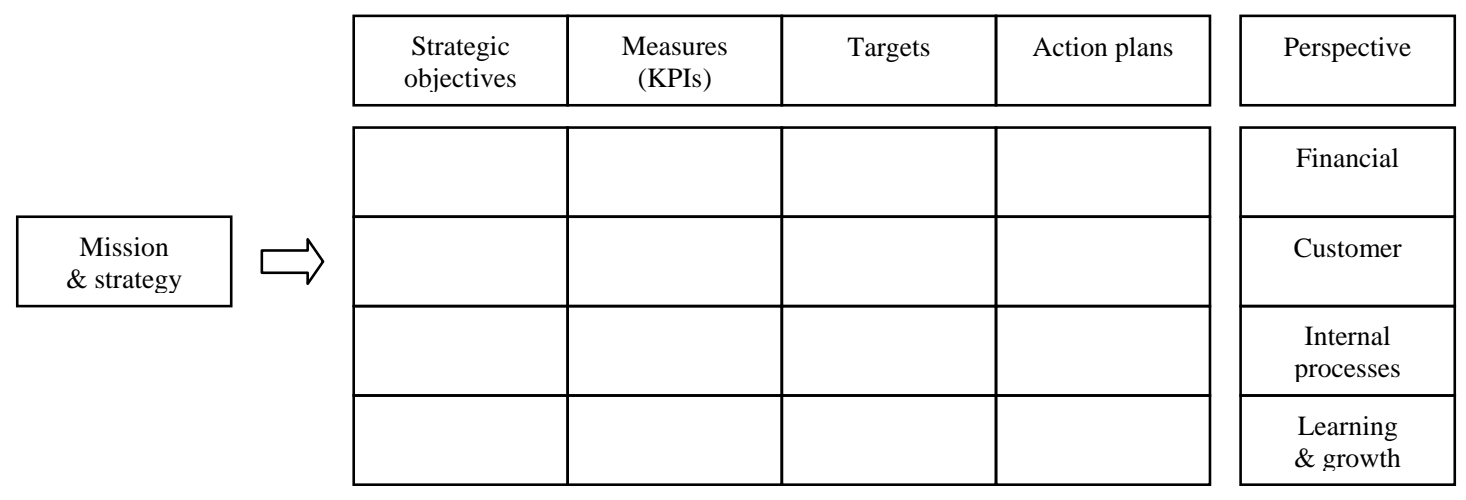

Figure 3: The balanced scorecard [49]

\subsubsection{The value added balanced scorecard integration}

In view of the fact that BSC describes a causal model for enhancing financial returns alone - disregarding the rest of the stakeholders who matter for the commercial success of the business - several scholars have tried to correct this anomaly. A potential approach is to adopt a different perspective: namely, cost, operations, organizations, health safety, and environment, paying proper attention to the most important conditions within the business $[8,26]$. In another approach, the use of the logic of the BSC and an adapted version of its framework to build the value-based concept is employed. The conceptual model that represents this is shown in Figure 4.

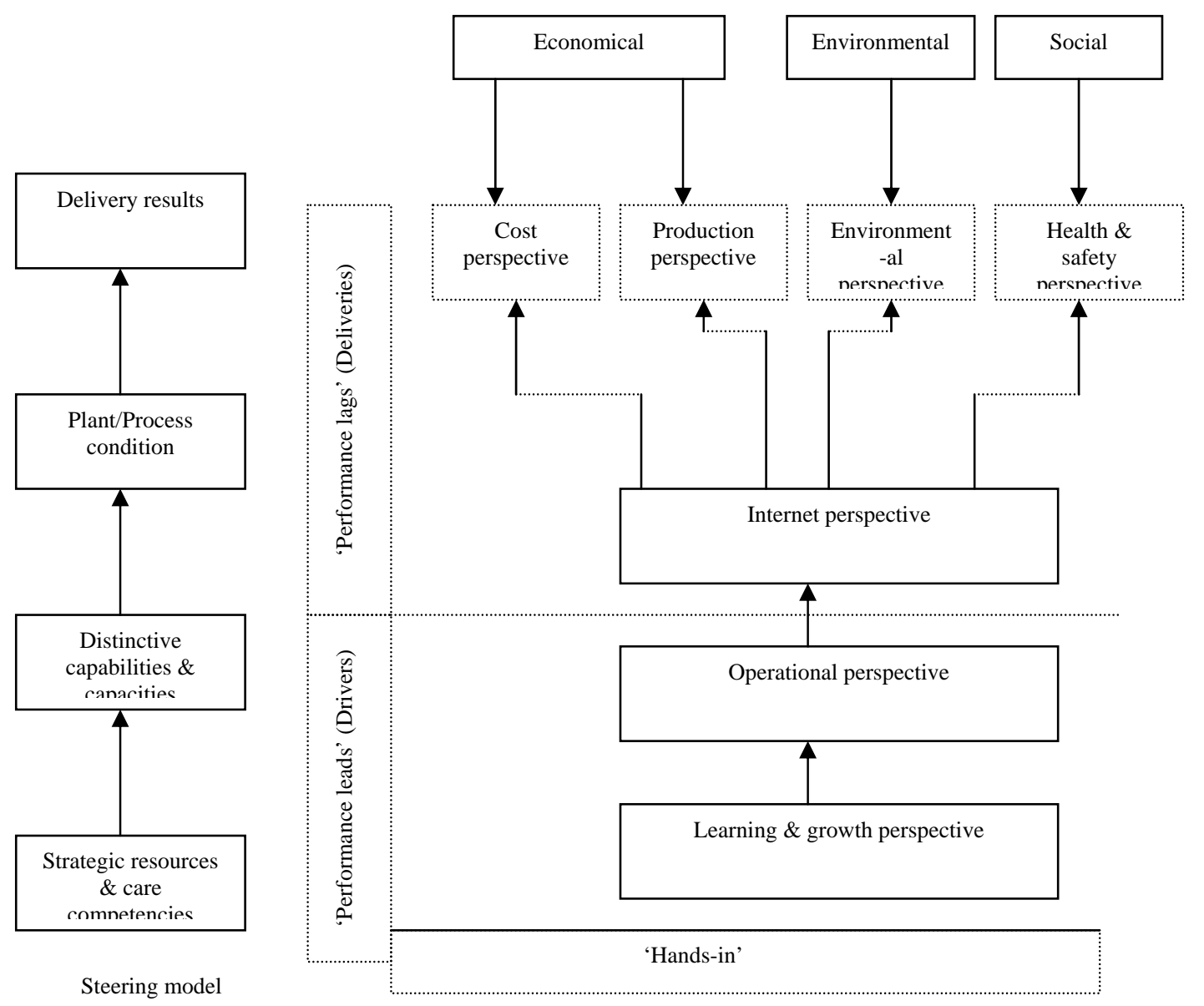

Figure 4: Balanced scorecard/value-based concept integration [26] 


\subsection{Reference numbers}

There are two categories of measures that fall under reference numbers: 'checklists' and 'survey'. Each is quantitative in nature. Checklists are referred to as 'quick' and 'dirty' performance indicators. They are widely used by consultants. Each indicator has an 'ideal' value or a range. A good example is the percentage of AGO lubricants that has a static level of stock value during the last three years. This should not be higher than 5 percent (Pintelon and Van Puyvelde [44]). The checklist approach provides a quick but rough insight into the information sought. In searching 'ideal' values a lot of difficulty is usually faced. The second class of reference numbers is 'surveys'. It is common to find such maintenance results published for specific industrial sectors such as steel, aluminium, glass, plastics, ceramics, furniture, etc, and to find academic research groups engaged in the use of such techniques. Pintelon and Van Puyvelde [44] point out that the result of such a survey may typically include maintenance cost as percentage of cost. Specifically, a range of $10 \%$ to $15 \%$ is given to technical research industries, while a value of $2 \%$ in pharmaceutical industries is recorded, etc. The research allows for low key benchmarking in specific sectors of the economy. However, a large deviation from the sector average may not necessarily mean that the performance is bad. In order to judge, a more detailed evaluation is needed (Pintelon and Van Puyvelde [44]).

\subsection{Graphs}

Graphs are quantitative in nature. They are of two types: (i) Diagrams and (ii) Radar graphs. Diagrams consist of well-known graphs such as pie charts, line and bar graphs. Each of these graphs has its own application area. From the experience of Pintelon and Van Puyvelde [44], pie charts are typically used where attention has to be drawn to the division of a whole into its components. A good example is the treatment of total cost, which may consist of material cost, labour cost, and subcontracting cost. This information may be useful when management is bothered by excessive spending in an aspect of maintenance service. Bar charts are used for picturing distributions. An example is the number of jobs which take less than 15 minutes, between 45-60 minutes, etc. [44]. Radar graphs are closely related to diagrams. Here, a number of indicators are brought together in one graph, and a scale defined for each of these indicators. The organization of the scales is like the spokes of a wheel: performance improves while moving to the centre. The hub indicates the target performance.

\subsection{Hibi's method}

This method is a very detailed approach that computes an integrated efficiency ratio (including repair or maintenance cost, and also downtime or maintenance related costs) and compares this ratio with a time control scale. The method developed for the Japanese steel industry is thorough but rigid [44]. 


\subsection{Maintenance management tool (MMT concept)}

The credit for the development of the MMT concept goes to the Center of Industrial Management at the Kuleuven. The tool consists of a control board (CB) that permits a quick evaluation of the maintenance performance in the past period, and a structured network of detailed reports (DR) which allows efficient diagnosis of the symptoms detected on the CB. This remedy may be organizational or tactical. An organizational remedy may involve changing the work order procedure, while a tactical remedy may involve increasing the preventive maintenance frequency. The MMT concept is presented in Figure 5.

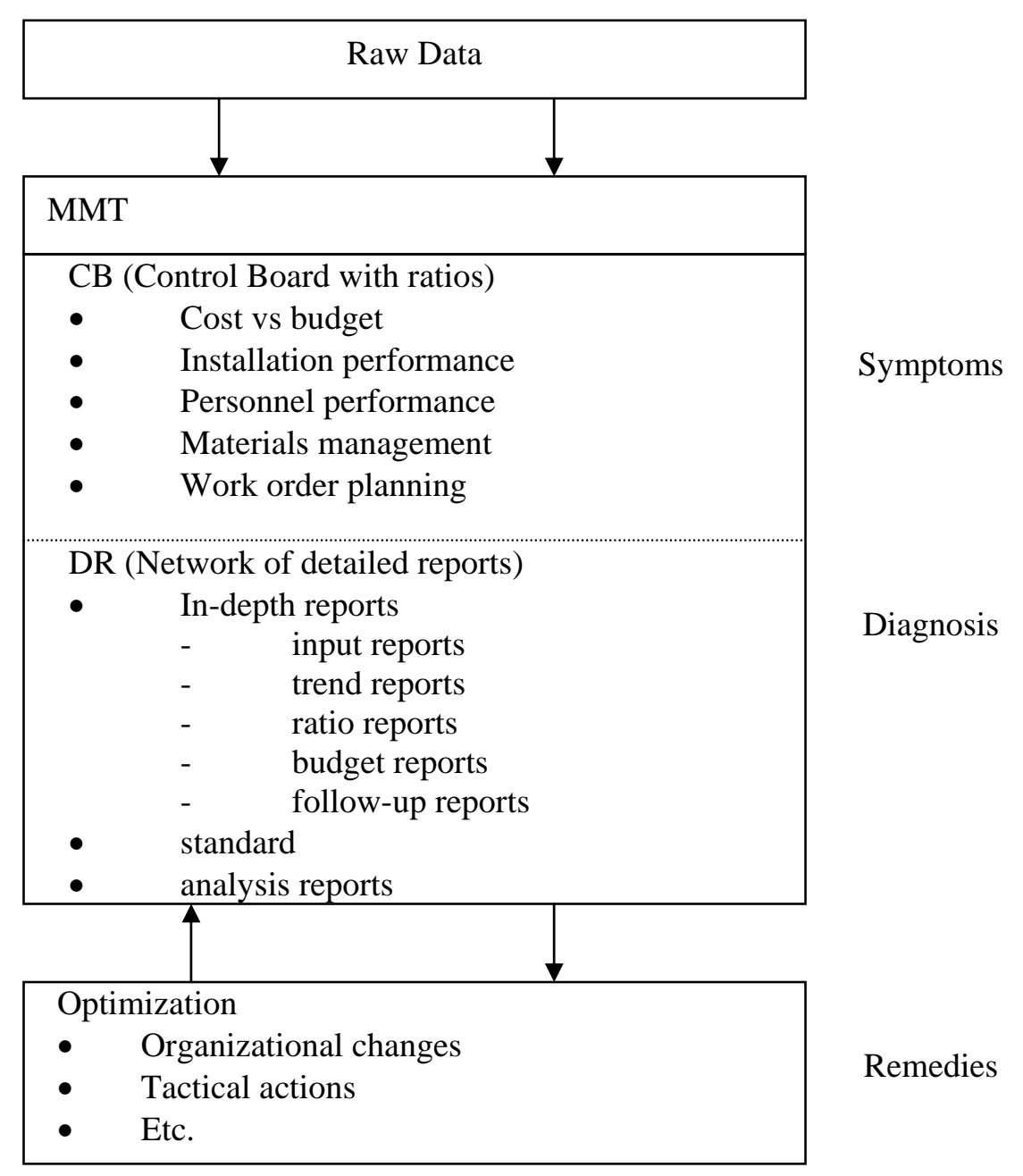

Figure 5: MMT Concept [44]

The CB provides information on five important aspects of maintenance performance. These five aspects consist of 20 different ratios which include: actual cost compared with budgeted cost, installation and personnel performance, materials management, and work order planning. A target value is given plus an appreciation of the difference between the two (e.g. 'acceptable' or 'requires immediate action'). The DR network allows one to disaggregate this ratio information up to the level of individual machines, individual work orders, etc. For this, the category of in-depth 
reports (featuring different sub-categories such as ratio reports, budget reports, follow-up or control reports and standard input reports) is appropriate. Other categories of DR are trend reports, which put the performance of the period in question in a time perspective, and analysis reports, which allow for a more explicit analysis of certain performance aspects (Pintelon and Van Puyvelde [44]).

\subsection{Qualitative approaches}

Two main qualitative approaches to the measurement of maintenance performance are reported in the current work. These are graph (multi-index profile) and Luck's method.

\subsubsection{Multi-index profile}

The graph gives a visual evaluation of the actual indicator values. Each indicator is represented on a scale where categorization of performance ranges from bad to excellent. Pintelon and Van Puyvelde [44] point out that for each indicator these scales may differ.

\subsubsection{Luck's method}

Luck's method is popular but old. It is graphically oriented (Figure 6). It consists of four maintenance performance aspects: bad, fair, good, and excellent. These aspects are on each side of the squares that show the measurement. The performance results of opposite sides are connected with lines; the intersection points indicate the global performance. In the original Luck concept, four such squares (work load, planning, cost, and productivity) are used; their results are summarized on a global evaluation picture in a final (fifth) square.

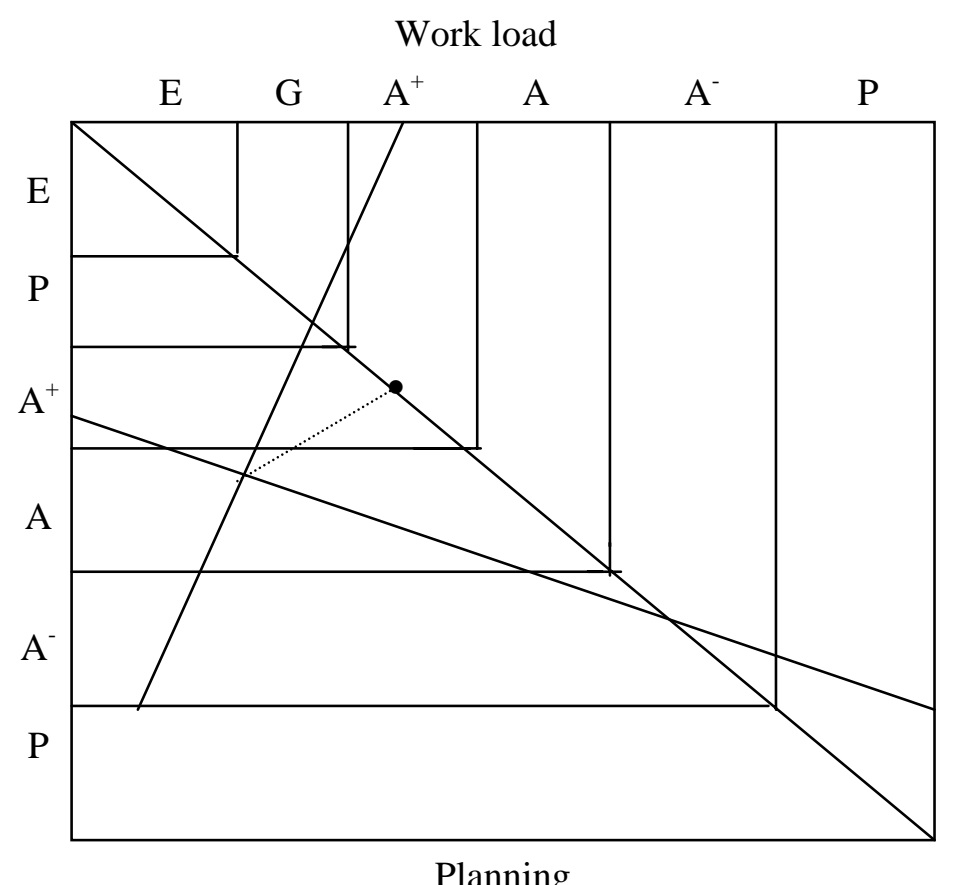

Figure 6: Luck’s method [44] 


\subsection{Criteria for the evaluation of approaches}

The following are the criteria for the evaluation of the various approaches reviewed in the work (see Table 1):

- Training required by user: This attribute refers to the level of training that the user of the model is expected to have acquired to enable proper use of the model. It is assumed that the user has taken courses in areas such as mathematics, physics, programming, statistics, etc. to understand the procedure and application of the model. The user must have had this training in an organized training environment. As part of the training, the user must have been severally assessed to determine the level of competence attained. Thus, in using the model, this criterion measures whether the training required is high or low.

- Accuracy of model: The model is expected to give the correct output result since the right data would be fed into the model. Thus, the correct input data must yield the correct output at all times. The model can be relied upon to give accuracy and consistency in processing the input data. In evaluating the input data, the model must give the corresponding and correct output information required. This implies that the processing capability of the model is strong enough to accept the required data input, and then releases the correct information needed to achieve a particular task.

- Clarity of model procedure: The model must show no ambiguity. It must be precise, clear, and distinct. The various steps involved in evaluation must not be hazy. Clarity in how to follow the procedure and interpret the result is of paramount importance. The procedure involved in usage must be clearly understood.

- Number of constraints of model: The constraints or limitations of the model must be well defined. Where the model will not function must be clearly spelt out. The boundary of the model's operation should be mapped, and the parameters both defined and undefined with respect to the model - should be stated. The limitations of the model function should be enumerated. These constraints are the factors or parameters that will not allow the model to function outside its boundary. The models are thus demobilized or limited in scope by these constraints. Therefore, here we consider the number of such constraints present in each model.

- Correctness of data input: It is clear that 'garbage in, garbage out' holds for any sequential-factored data system model. For the result of model evaluation to be correct, the input data must - as a matter of necessity - be correct. To avoid error right from the start, the model user must ensure the correctness of the data input, and therefore of data computed. The values must be checked for homogeneity in units, readings, computations, etc. 


\begin{tabular}{|c|c|c|c|c|c|c|c|c|}
\hline $\mathrm{S} / \mathrm{N}$ & $\begin{array}{l}\text { Criteria for evaluating various } \\
\text { approaches }\end{array}$ & 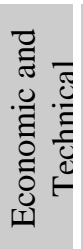 & 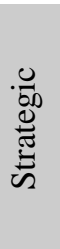 & 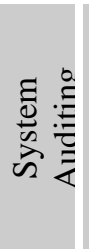 & 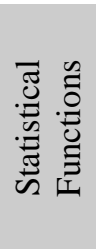 & 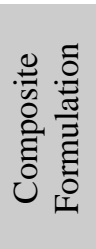 & 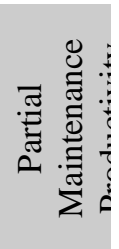 & 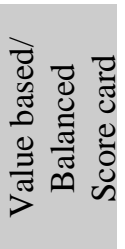 \\
\hline 1. & Training required by user & 3 & $\square$ & 2 & 4 & 1 & $\bullet$ & 2 \\
\hline 2. & Accuracy of model & 2 & 3 & 2 & $\Delta$ & 3 & $\square$ & $\square$ \\
\hline 3. & Clarity of model procedure & $\square$ & $\bullet$ & 3 & $\bullet$ & 3 & $\square$ & $\square$ \\
\hline 4. & No. of constraints of model & 4 & 4 & 2 & 3 & 3 & 4 & 4 \\
\hline 5. & Correctness of data input & $\square$ & $\square$ & 2 & 4 & 4 & 2 & 3 \\
\hline 6. & Assessment ability by user & 3 & $\square$ & 2 & $\Delta$ & $\bullet$ & $\square$ & 3 \\
\hline 7. & Mathematical soundness of model & $\mathrm{X}$ & $\bullet$ & $\square$ & $\bullet$ & $\bullet$ & $\square$ & $\mathrm{X}$ \\
\hline 8. & Logical soundness of model & $\mathrm{X}$ & $\square$ & $\square$ & $\bullet$ & $\bullet$ & $\square$ & $\mathrm{X}$ \\
\hline 9. & Experience requirement of user & 3 & $\square$ & 2 & 1 & 2 & 3 & 2 \\
\hline 10. & Non-ambiguity of input data & $\square$ & 2 & 2 & 3 & $\square$ & 2 & $\square$ \\
\hline 11. & Practicality of model & 3 & 2 & 3 & $\Delta$ & $\square$ & 2 & 2 \\
\hline 12. & Effectiveness of model & 2 & $\bullet$ & 3 & 4 & - & 2 & 2 \\
\hline 13. & $\begin{array}{l}\text { Correct interpretation of result by } \\
\text { user }\end{array}$ & $\square$ & 2 & $\square$ & 4 & $\bullet$ & 2 & $\square$ \\
\hline 14. & Number of input values needed & 2 & $\bullet$ & 1 & 2 & 4 & 4 & 3 \\
\hline 15. & Number of steps & 2 & 4 & 2 & 4 & 3 & 4 & 3 \\
\hline 16. & Does it involve making comparisons? & 4 & 4 & $\Delta$ & 4 & 4 & 5 & 2 \\
\hline 17. & Computational complexity & 2 & $\Delta$ & 2 & 4 & - & 4 & 3 \\
\hline 18. & Capabilities of model & $\square$ & 3 & $\square$ & $\Delta$ & 3 & 2 & 2 \\
\hline 19. & Faulty design of model & 5 & $\Delta$ & 4 & $\bullet$ & 3 & 4 & 4 \\
\hline 20. & Inherent weaknesses of model & 4 & 4 & 4 & 2 & 2 & 3 & 4 \\
\hline 21. & Wide utilization of model & $\square$ & $\square$ & $\Delta$ & $\Delta$ & $\Delta$ & 4 & 1 \\
\hline 22. & Sensitivity of model parameters & 2 & 3 & $\square$ & 2 & $\bullet$ & $\bullet$ & $\square$ \\
\hline 23. & Consistency of model parameters & $\square$ & 3 & $\square$ & 4 & $\bullet$ & $\bullet$ & - \\
\hline 24. & Presentation of model & $\square$ & 4 & $\square$ & $\Delta$ & $\Delta$ & $\square$ & $\square$ \\
\hline 25. & Readily availability of input data & $\Delta$ & 3 & $\Delta$ & $\Delta$ & $\Delta$ & $\bullet$ & $\square$ \\
\hline
\end{tabular}

Key 1:

$\begin{array}{llll}\text { Very good } & \mathrm{X} & \text { Very high } & 1 \\ \text { Good } & \square & \text { High } & 2 \\ \text { Average } & \bullet & \text { Average } & 3 \\ \text { Poor } & \Delta & \text { Low } & 4 \\ \text { Very poor } & \Rightarrow & \text { Very low } & 5\end{array}$

Table 1: An evaluation of the various approaches used in the measurement of maintenance performance

- Assessment ability by user: The model user must be able to assess or evaluate the performance of the model in terms of its operation and results. More importantly, the user must know how to assess, analyze and interpret the end 
result of computation to discover hidden knowledge embedded in the operation of the model.

- Mathematical soundness of model: In the derivation and use of the model, the mathematics involved in the various steps must be clear and sound. From the start, the step-by-step development of the model's mathematics and attributes must establish accuracy and soundness. The building blocks of topics (such as probability, series and summation, inequality, etc.) must be based on logical reasoning and rational usage. The need for sound mathematics in the the model's development and generated results cannot be over-emphasized.

- Logical soundness of model: The logic inherent in the development of model must be sound. The model must be logically arrived at, and effectively utilized.

- Experience requirement of user: This defines the level of experience required by the user of the model. Experience is measured in terms of proper model analysis based on usage of similar models for analysis. A new user will have to go to greater lengths to carry out the evaluation task. Therefore, the level of experience required by the user is a necessary criterion in proper analysis of model results.

- Non-ambiguity of input-data: The data input to the model must be distinct. It must not be ambiguous or misrepresented. It must show clarity and uniqueness.

- Practicality of model: The model must be easy to use in practice. It should be convenient for application to real life situations. Real attributes of performance must be displayed in the working of the model. Thus, the model has an immediate significant influence on systems operations and on the final result. A model must be easily adaptated and yield correct results when subjected to a reallife working environment. The model should be feasible and workable.

- Effectiveness of model: The model must be able to produce the correct result that is required or intended. The model can display expected and reliable output information by properly coordinating its processing of data. The difference in values generated by the model from the actual correct values indicates the degree of error, and is a measure of model effectiveness.

- Correct interpretation of result by user: The way the user views, understands and explains the model's procedure and results will affect the application of the model. The user must ensure correct and adequate analysis and evaluation of model results.

- Number of input values needed: The model's input values should be minimal. The input values should be as few and concise as possible. In a working environment, the fewer the input parameters, the less cumbersome the computation, and the higher the functionality of the user and model will be. 
- Number of steps: The different steps or stages involved in the model procedure should also be as few as possible. The link from one step to the next should also be logical.

- Does it involve making a comparison?: Models should be carefully compared with others to reveal similar or different patterns. This comparison would show hidden knowledge concerning the result, and how interrelated the models are.

- Computational complexity: The mathematical computations must not be too complicated or clumsy so as to cause difficulty in understanding and usage. Clarity and simplicity should be a prominent feature of the model.

- Capabilities of the model: The model should be able to carry out the task of computing, processing and presenting the input data to give accurate output data. It should cover a wide range of input data with few or no exceptions.

- Faulty design of the model: The model is designed to work correctly and is free from error. Faulty design can lead to poor evaluation and processing of data.

- Inherent weaknesses of the model: Any weakness embedded in the model right from its design stage is an obstacle to its effective performance. This basic fault or weakness limits the application of the model.

- Wide utilization of the model: Use of the model in wide areas of application is a pointer to its effectiveness. It must be limited by few or no constraints. A good model should accurately process a wide range of input data.

- Sensitivity of the model parameters: This implies that parameter input to the model must respond to small changes in factors producing them.

- Consistency of the model parameters: Input parameters should develop in a consistent manner. Its derivation should be regular.

- Presentation of the model: The model's procedure and result presentation should be clearly made, without obscurity. Results should not be capable of many interpretations.

- Ready availability of input data: The data input should be readily available at all times. It should not be difficult to obtain.

\section{MAINTENANCE PERFORMANCE IN THE SOFTWARE AREA}

The discussion here centres on two main perspectives. First we review the previous work that has been done to improve on the performance of software maintenance systems. The second group of studies relates to the software developed to monitor maintenance systems. 
For a number of years, computerised maintenance management systems (CMMS) have been the focus for companies wishing to improve their asset management strategy. During this period much has been promised but little has been learned, and even less has been delivered in terms of improved plant performance.

The paper by Geraghty [12] examines some of the misconceptions about CMMS use and about the more common performance indicators. An assessment is then made of (a) the kind of information that can realistically be expected from a properly implemented system, and (b) what needs to be done in order to make a difference.

In an article on software maintenance, Sneed [48] observed that over half of an average data processing user staff is committed to maintaining existing applications. However, as opposed to software development - where productivity is measured in terms of lines of code, function-points, data-points or object-points per person month, and quality is measured in terms of deficiencies and defect rates per test period - there are no established metrics for measuring the productivity and quality of software maintenance. This means that over half of an organisation's software budget cannot be accounted for. The costs occur without being able to measure the benefits obtained. A set of metrics is proposed for helping to remedy this situation by measuring the productivity and quality of the maintenance service.

\section{IMPLICATIONS FOR RESEARCHERS AND MANAGERS}

One of the features of maintenance performance literature in recent years has been the growth of the field. This section of the paper is written primarily to explain our projections for the future development of the maintenance performance area. It explains, simply and concisely, the future trends of maintenance performance research while providing a profitable challenge to investigators.

The future of maintenance performance is promising, with opportunities for system modelling, specific applications in industries, and general surveys. System modelling will experience an explosion with new streams of modellers joining the flow.

In addressing the questions and concerns raised by the literature on maintenance performance research, a number of research opportunities and directions are apparent. Clearly, the area of greatest deficiency is that of analytical refinement and explication. Firstly, researchers need to agree on a universal meaning of 'maintenance performance'. Only then could a meaningful theory be developed. This, in turn, would facilitate improved measurement, analysis, and control of systems.

When specifically viewed from the analytical perspective, the analytical hierarchy process stands out as an important tool in maintenance performance research. The application of the analytical hierarchy process presents a promising tool of development in maintenance performance research. The analytical hierarchy process is expected to expand steadily to cover a whole range of maintenance diagnostic tools: scheduling, performance measurement, budgeting, allocation problems, location of maintenance facilities, etc. It would also extend across industries such as 
oil, manufacturing, transportation, and mining, and the range can be expected to expand considerably. The extension of the analytical hierarchy process into maintenance performance may be a major development both academically and practically, and could open up speculation and research on a wide range of problems.

The past several years have witnessed the development of models and considerable understanding of the technical matters of maintenance performance, which were only vaguely understood in recent decades. Investigators have a lot still to do; the most important remaining work is in the category of optimisation techniques and error analysis.

Established tools of operations research that have been profitably applied in other areas may also be successfully employed in maintenance performance research. For example, operations research involves the application of scientific methods to the management of maintenance performance problems that involves complex systems of people, machinery, material, money, and information. Investigation of operations research problems in maintenance performance will seek to produce an understanding of maintenance management problems and to develop models, which will enable the consequences of maintenance decisions to be investigated. Operations research methods have already had widespread application and success in many areas of business, industry, and government, and their use is rapidly increasing in the international arena.

While the science of maintenance performance is not yet robust, it is educated. Serious work on maintenance performance is expected to develop an arsenal of optimisation techniques to deal with the current problems in the field. In addition, the maintenance performance literature should attack the problem of usability by developing user-friendly proprietary packages. Obviously, we now have considerably more computer power than current problems in maintenance performance could need. Thus, we have a population of problems that should keep researchers and practitioners investigating maintenance performance for several decades.

Most of the studies are concerned with the traditional function of measurement. However, the present decade promises real strength of maintenance performance in terms of auditing, with the adoption of the principles of financial custodianship and custodianship of physical assets. The principles of financial custodianship - the process at the heart of financial custodianship - will be successfully applied to maintenance performance. Pacioli's ideas of 1494 will be revisited but applied to the maintenance performance field. This means that all financial and non-financial transactions relating to maintenance performance should be accounted for, and proper books and records kept at the end of every accounting period.

The procedures and documentation that are required to make this process work should become part of the way we do business. Governments should intervene, making it a statutory requirement to keep maintenance books and records. Maintenance performance auditing should then be considered for effective 
management of the system. Maintenance auditors should adopt an investigatory approach to maintenance performance, from the perspective of preserving resources.

Serious efforts should be directed towards resource utilisation. A whole new area would then be opened up to maintenance auditors because they are responsible for assessing the utilisation of company's assets. An appraisal of maintenance management techniques that are employed, and the basis of establishing maintenance budgets and forecasts, should be the maintenance auditor's concern. Also, for proper decision-making, the maintenance auditor should objectively assess the financial and non-financial worth of maintained facilities.

Given the efforts, needs, capabilities and expertise, knowledge, and talents now devoted to maintenance performance problems, the next few decades promise much activity, high quality investigation results, and fruitful research and practice in maintenance performance studies.

\section{FUTURE DIRECTIONS OF MAINTENANCE PERFORMANCE RESEARCH}

Future research efforts on maintenance performance need to be directed to some areas that have not been documented. These areas may include the application of some established tools of operations research, since the field has several optimisation techniques which, when introduced to maintenance performance measures, would add great value. It might be interesting if scholars investigated the application of linear and non-linear programming techniques to maintenance performance. This would bring another dimension to maintenance performance, which may eventually become a field on its own. The concept of game theory may also prove very useful for future research. With the proper applications of these tools, results similar to those obtained in manufacturing are likely. Thus, we may expect to save significant amount of money from the application of these tools in large and complex industrial systems.

This anticipated increased and widespread optimisation of maintenance performance research will be further stimulated by the availability of digital computers, and the necessity of using them in the investigation of large systems.

\subsection{Composite model formulation}

The campaign on the use of composite models is intensive. Efforts have also been made towards its implementation in industries. In the next few decades, approaches to developing composite models should emerge. There is a need to investigate the shortcomings usually caused by implicit redundancies and over-emphasis of component measures. Consequently, numerical solutions with optimal results will be developed and exercised over a wide range of composite indices. Reported results should highlight some common problems faced in the development of composite maintenance performance measures. Indeed, the recent comments of investigators on maintenance performance have challenged researchers and practitioners to rethink many of the fundamental approaches to model development. Research and 
theoretical developments are needed to address several central elements of an holistic (or integrated) perspective. The idea of composite model formulation is intended to be a further step in advancing existing literature towards broader maintenance performance perspectives.

\subsection{Analytical hierarchy process approach}

As a result of composite model formulation, the need to prioritise measures of a broad category in an holistic form requires the development of accepted approaches. An adequate evaluation of this scenario has not yet been published. Thus, extensive application of the analytical hierarchy process is awaited. Until this is done, and a reliable estimate made, the available approaches remain limited. Consequently, more investigations are required in order to reach definite and reliable conclusions.

\subsection{Sensitivity analysis}

The prediction of optimal maintenance performance models, their calibration, sensitivity analysis, and application should add to research into maintenance performance. The purpose of the model would be to provide a quantitative description of the interactions that occur between component variables. Future studies should also investigate the consequences of these interactions. The maintenance performance models require calibration with field data from the system that they seek to simulate. When there are many interactive state variables, it is important to ascertain those parameters to which the model results are most sensitive. Once identified, these parameters are the ones towards which most of the calibration efforts should be directed.

Future research should quantify the sensitivity of the model parameters in many ways, typically through examining changes in the major state variables. The test of the calibration, values selected, and the validation, is the degree to which the model prediction matches field data. Insights into the numerous mathematical techniques to calibrate model parameters will add value to the future literature on maintenance performance. Validating future models should be achieved with predictions from a model that has been calibrated and verified with data sets. This will give a good approximation of the behaviour of the databank. Once complete, validation would indicate that the model could be used as a tool to make progress with the system for which it was calibrated.

\section{CONCLUSIONS}

It should be emphasized that the value based concept complements some popular movements today. These schools of thought may include total quality, system, process, and balanced assessment.

A full-scale application of the value based concept calls for a rich infrastructure, and an organizational culture that promotes the assumption of the subject matter and its reception as an effective tool in management performance [26]. Two key issues that relate to the success of value based concept application in manufacturing 
organizations are responsibility and authority. It is important to know which responsibilities are assigned to process owners, and the scope and the scale of such assignment. Also, it is necessary to understand whether necessary and essential authority has been delegated to process owners to make decisions and take actions in respect of the responsibilities assigned, and that any limitations imposed in this respect are clearly defined [26].

\section{REFERENCES}

[1] Armitage P., Jardine, A.K.S., 1968. “A decision problem”, International Journal of Production Research, Vol. 7, No. 1, pp. 7 - 15.

[2] Dwight, R. A. 1994. "Performance indices: do they help with decision making?”, Proceedings of ICOMS-94, Sydney, Paper 12, pp. 1-9.

[3] Dwight, R. 1995. "Concepts for measuring maintenance performance", in Martin, H.H. (Ed.), New Developments in Maintenance: An International View, IFRIM, Eindhoven, pp. 109 - 125.

[4] Dwight, R. 1999. "Frameworks for measuring the performance of the maintenance system in a capital intensive organization", $\mathrm{PhD}$ Thesis, Department of Mechanical Engineering, University of Wollongong, Wollongong.

[5] Dwight, R., 2002. "In search of element influence analysis“, in Proceedings of the International Foundation for Research in Maintenance, Maintenance Management and Modelling Conference, (IFRIM-2002), Vaxjo University, Sweden.

[6] Dwight, R., 2002. "Performance measurement and review utilising system element influence analysis", in Proceedings of the International Foundation for Research in Maintenance, Maintenance Management and Modelling Conference, (IFRIM-2002), Vaxjo University, Sweden.

[7] Dwight R., 1999. "Searching for real maintenance performance measures", Journal of Quality in Maintenance Engineering, Vol. 5, No. 3, pp. 258-275.

[8] Ellingsen, H.P. et al. 2002. "Management of assets, resources and maintenance by using a balanced scorecard based performance framework", Proceedings of the $16^{\text {th }}$ International Maintenance Conference: Euromaintenance - 2002, pp. 203-211.

[9] Ellingsen H. P., Kumar U., Liyanage J.P., Tønnesen N., Hamre R., Nilsen N. M., Waldeland R., Nerhus O., Espeland Ø., 2001. "Development of a methodology for the usage and implementation of operation \& maintenance performance indicators (task 7-d)", Project on the Development and Implementation of Operations \& Maintenance (O\&M) Performance Indicators, PI-TEC-T7\&9/REV0.

[10] Ellingsen H. P., Tønnesen N., Hamre R., Nilsen N. M., Waldeland R., Nerhus O., Kumar U., Espeland Ø., Liyanage J.P., 2001. "Development of a performance framework (task 6-b)", Project on the Development and Implementation of Operations \& Maintenance $(O \& M)$ Performance Indicators, PI-TEC-T6/REV0.

[11] Geraerds W.M.J., 1990. “The EUT-maintenance model”, IFRIM-report 90/01, Eindhoven. 
[12] Geraghty T., 1995. "The truth about computer systems and performance indicators in maintenance", Journal of Maintenance and Asset Management, Vol. 10, No. 1. (January).

[13] Hemu, M., 2000. "Using benchmark data effectively sustainable maintenance performance targets in our industry”, Journal of Maintenance and Asset Management, Vol. 15, No. 3. (July/August).

[14] Kaplan R.S. and Norton D.P., 1992. "The balance scorecard-measures that drive performance”, Harvard Business Review, January-February, pp. 71-79.

[15] Kaplan R.S. and Norton D.P., 1993. "Putting the balanced scorecard to work”, Harvard Business Review, Vol. 71, No. 5, pp. 134-142.

[16] Kaplan R.S. and Norton D.P., 1996. "Using the balance scorecard as a strategic management system”, Harvard Business Review, January-February, pp. 75-84.

[17] Kay, E., 1976. “The effectiveness of preventive maintenance”, International Journal of Production Research, Vol. 14, No. 3, pp. 329-344.

[18] Kincaid D.G., 1994. "Measuring performance in facility management", Facilities, Vol. 12, No. 6, pp. 17-20.

[19] Kumar, U. and Ellingsen, H.P. 2000. "Development and implementation of maintenance performance indicators for the Norwegian oil and gas industry”, Proceedings of the Euromaintenance-2000 Conference, pp. 221-226.

[20] Kumar U., Liyanage, J., 2000. “A strategically balanced measurement system for maintenance process: Some foundational issues for a development method (Part II)”, Maintenance \& Operations, Vol. 4, No. 3, pp. 147-155.

[21] Kumar U., Liyanage, J., 2000. "On the attempt to streamline maintenance process using a value based performance measurement system”, Maintenance Day - 2000 Seminar, Lulea, Sweden.

[22] Kumar U., Liyanage, J., 2002. “A value based working algorithm to manage maintenance performance: Key learning points from the oil \& gas industry about an integrated production asset”, New Engineer Journal, Vol. 4, No. 4, pp. 5-7.

[23] Kumar U., Liyanage, J., 2002. “Adjusting maintenance policy to business conditions: Value-based maintenance performance measurement”, in Proceedings of the International Foundation for Research in Maintenance, Maintenance Management and Modeling Conference, , Vaxjo, Sweden, Paper No. 20.

[24] Kutucuoglu K.Y.; Hamali J.; Irani Z.; Sharp J.M., 2001. “A framework for managing maintenance using performance measurement systems" International Journal of Operations \& Production Management, Vol. 21, No. 1/2, pp. 173-194.

[25] Labib, A.W.; O'Conor R.F.; Williams G.B., 1998. "An effective maintenance system using the analytical hierarchy process", Integrated Manufacturing Systems, Vol. 9, No. 2, pp. 87-98.

[26] Liyanage, J.P., et al. 2003. "Development of indicators (Task 5)", Project on the Development and Implementation of Operations \& Maintenance (O\&M) Performance Indicators, PI-TEC-T5/REV0.

[27] Liyanage, J.P., Kumar, U., 2000. "On the attempt to streamline maintenance process using a value based performance measurement system”, Maintenance Day - 2000 Seminar. 
[28] Liyanage, J.P., Kumar, U., 2001. "Value based maintenance performance diagnostics: An architecture to measure maintenance performance in petroleum assets”, The International Conference of Maintenance Societies (ICOMS2001), Paper no. 050.

[29] Liyanage, J.P., Kumar, U., 2002. “A value-based working algorithm to manage maintenance performance: Key learning points from oil \& gas industry about an integrated production asset”, New Engineer Journal, Vol. 4, No.4, pp 5-7.

[30] Liyanage, J.P., Kumar, U., 2002. "Process of maintenance performance management and its imperatives within the offshore petroleum industry (PartII): The principles of value based maintenance performance management”, SMRP Solutions, Issue 2.

[31] Liyanage, J.P., Kumar, U., 2002. "Process of maintenance performance management and its imperatives within the offshore petroleum industry (PartIII): Integration of maintenance performance to corporate value process", SMRP Solutions, Issue 3.

[32] Liyanage, J.P., Kumar, U., 2002. "Value based maintenance performance management for the petroleum industry”, Proceedings of the 4th International Conference on Quality, Reliability, Maintenance (QRM-2002), pp 113-116.

[33] Liyanage, J.P., Kumar, U., 2002. "Value based maintenance performance management for the petroleum industry”, To appear in Measurement and Control Journal.

[34] Liyanage, J.P., Kumar, U., 2002. "Value based management of maintenance performance: The best practice for the 21st century maintenance based on experiences \& learning from oil \& gas industry”, Proceedings of the 16th European Maintenance Congress: Euromaintenance 2002, pp 29-36.

[35] Liyanage, J.P., Kumar, U., Osmundssen, P., 2001. "A pathfinder for value based maintenance in the 21st century: A structured technique for an operations \& maintenance scorecard for process industries”, The 3 rd Middle East Refining \& Petrochemicals Exhibition \& Conference (PETROTECH2001), Paper PN-068.

[36] Liyanage, J.P. et al. 2001b. "Risk and value: a basis for balancing maintenance performance in offshore engineering constructions", Proceedings of the $11^{\text {th }}$ International Offshore and Polar Engineering Conference 2001, vol. iv, pp. 529-536.

[37] Liyanage J., Kumar U., 2003. "Towards a value-based view on operations and maintenance performance management” Journal of Quality in Maintenance Engineering, Vol. 9, No. 4, pp. 333 - 350.

[38] Luck W.S., 1965. "Now you can really measure maintenance performance, Factory Management and Maintenance”, McGraw-Hill, Vol. 114, pp. 81-86.

[39] Martorell, S., Sanchez, A., Muñoz, A., Pitarch, J.L., Serradell, V., Roldan, J., 1999. "The use of maintenance indicators to evaluate the effects of maintenance programs on NPP performance and safety", Reliability Engineering and System Safety, Vol. 65, Issue 2, pp. 85-94.

[40] Mobley, R.K., 1998. Total plant performance management, TWI Press, Inc.

[41] Oke, S.A., Oluleye, A.E., 1999. “A template for composing maintenance performance measures", Conference Proceedings of the Nigerian Institute of Industrial Engineers, pp. 114-125. 
[42] Oluleye, A.E., Tade, A.O., Olajire, K.A., 1997. "A schema for assessing maintenance effectiveness", $7^{\text {th }}$ International Management of Industrial Reliability and Cost Effectiveness Symposium, University of Exeter, United Kingdom, pp. 331 - 341.

[43] Perry, D. and Starr, A.G. 2001. "Introducing value based maintenance”, in Starr, A.G. and Rao, R.B.K.N. (Eds), Condition Monitoring and Diagnostic Engineering Management, Elsevier Science, Amsterdam.

[44] Pintelon, L., Van Puyvelde F., 1997. "Maintenance performance reporting systems: some experiences”, Journal of Quality in Maintenance Engineering, Vol. 3, No. 1, pp. 4-15.

[45] Priel, V.Z., 1962. "Twenty ways to track maintenance performance”, Factory

[46] Priel, V.Z., 1974. Systematic Maintenance Organisation, MacDonald \& Evans Ltd., London.

[47] Raouf A., 1993. “On evaluating maintenance performance”, International Journal of Quality \& Reliability Management, Vol. 10, No. 3.

[48] Sneed, H.M., 1997. "Measuring the performance of a software maintenance department", Proceedings of the 1st Euromicro Working Conference on Software Maintenance and Reengineering (CSMR '97), Spain.

[49] Tsang A.H.C., Jardine A.K.S., Kolodny H., 1999. "Measuring maintenance performance: a holistic approach”, International Journal of Operations \& Production Management, Vol. 19, No. 7, pp. 691-715.

\section{Acknowledgement}

The author gratefully acknowledges the immense contributions of the anonymous reviewers of this paper. He also thanks Professor J.K. Visser, University of Pretoria, South Africa, and Joel Levitt of Maintenance Trainers, Inc., USA for their comments on earlier drafts of this article. In addition, thanks to Professor A. E. Oluleye, under whose guidance related research was conducted while the author was a student at the University of Ibadan, Nigeria. 